
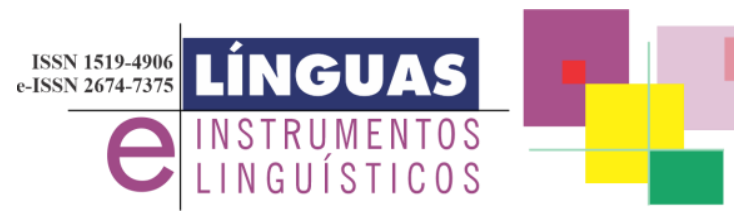

DOI: $10.20396 /$ lil.v24i48.8665738

\title{
Uma abordagem enunciativa da autoria
}

\author{
An enunciative approach to authorship
}

\section{Gabriele Cristine Carvalho* IFMG}

\section{Luiz Francisco Dias** \\ UFMG}

Resumo: Considerando elementos conceituais de Bakhtin (2011a, 2011b), Foucault (2000, 2018), Barthes (2012a, 2012b), Orlandi (2015) e Indursky (2001) sobre autoria, este artigo apresenta uma abordagem enunciativa do conceito de autoria, partindo dos trabalhos de Dias (2015a, 2015b, 2018) na Semântica da Enunciação. Utilizando o quadro teórico desenvolvido por Dias, defendemos que a funçãoautor organiza o texto na delimitação de um ponto de vista, que é ancorado por referenciais históricos que se tornam pertinentes por conformações interativas e de articulação. A análise do conceito de autoria em uma redação nota 1.000 do ENEM 2018 mostra sua aplicabilidade nesse tipo de produção escrita.

Palavras-chave: Autoria, Ponto de vista, Semântica da Enunciação, Redação do ENEM.

Abstract: Considering conceptual elements formulated by Bakhtin (2011a, 2011b), Foucault (2000, 2018), Barthes (2012a, 2012b), Orlandi (2015) and Indursky (2001) on authorship, this paper presents an enunciative approach of authorship concept, starting from Dias's theory $(2015 a, 2015 b, 2018)$ in the Semantics of Enunciation. Based on Dias's theorical framework, we claim that author-function organizes 
the text in the delimitation of a point of view, which is anchored by historical references that become pertinent by interactive and articulation conformations. The analysis of the authorship concept in a total score 2018 ENEM essay shows its applicability in this kind of written production.

Keywords: Authorship, Point of view, Semantics of Enunciation, ENEM essay.

\section{Introdução}

A autoria é um conceito discutido há bastante tempo e por autores de diversos campos de estudo e posições teóricas. Dois aspectos perpassam a maior parte dessas obras, constituindo o interesse maior no presente estudo: o papel do autor na textualização e o grau de personalização da autoria na investida temática.

À luz da Semântica, mais especificamente, a partir dos trabalhos de Dias (2015a, 2015b, 2018), desenvolvemos os dois aspectos acima, com vistas a formular uma concepção de autoria do ponto de vista dos estudos enunciativos.

Dias (2018) defende que os nossos dizeres têm uma filiação, baseiam-se em referenciais históricos, que se tornam pertinentes quando adquirem conformações de articulação e conformações interativas. Seguindo essa abordagem, advogamos que a função de autoria organiza o texto em torno de um ponto de vista, ancorando-se em referenciais históricos, que se tornam pertinentes por meio de conformações interativas e de articulação. A partir dessas diretrizes em torno da autoria, analisamos uma redação nota 1.000 do ENEM 2018, observando como os traços de articulação e de interação temática configuram a pertinência enunciativa do texto, produzindo as condições para a emergência da autoria que se almeja para o gênero amparado pelos idealizadores do exame.

Acreditamos que nossa concepção de autoria pode permitir um novo olhar para a produção escrita escolar e para a preparação de candidatos nos exames de seleção. 


\section{Percurso histórico da concepção de autoria: o que é mesmo um autor?}

Traçaremos um panorama mínimo das concepções de autoria, levantando formulações sobre o tema já bastante assentadas. Particularmente, vamos buscar nessas concepções a relação entre a autoria e textualização.

Para Foucault, inexoravelmente, a autoria estaria ligada à existência de uma obra que pudesse estabelecer diferença significativa numa conjuntura de posicionamentos discursivos. Nessa perspectiva, haveria discursos sem autoria, como "as conversas cotidianas, logo apagadas; decretos ou contratos que precisam de signatário, mas não de autor, receitas técnicas transmitidas no anonimato" (FOUCAULT, 2000, p. 26-27). Por outro lado, os textos autorais indicariam que não se trata de "um discurso quotidiano, indiferente, um discurso flutuante e passageiro, imediatamente consumível" (FOUCAULT, 2018, p. 45). Nessa concepção, há um "desnivelamento dos discursos": os discursos do dia a dia seriam comentários, "que repetem, glosam e comentam" e os que requerem autoria seriam "os discursos fundamentais ou criadores" (FOUCAULT, 2000, p. 23).

Segundo Foucault, a autoria seria "um princípio de agrupamento do discurso, como unidade e origem de suas significações, como foco de sua coerência" (FOUCAULT, 2000, p. 26). Nesse sentido, o autor não deve ser confundido com o sujeito empírico que criou o texto, visto que, dentre as várias posições que o sujeito pode ocupar na sociedade, a posição enunciativa de autor é uma delas e, portanto, deve ser tratada como uma função. A autoria estaria relacionada a uma obra ou texto, trazendo uma materialidade que a faz perdurar no tempo, diferenciando-se dos discursos orais, que são fugazes.

Essa densidade na concepção da autoria não se verifica no famoso texto de Barthes (2012a), "A morte do autor", em que sustenta que "o nascimento do leitor deve pagar-se com a morte do autor" (p. 64). O leitor teria esse poder, porque, segundo ele, em primeiro lugar, o texto "é um tecido de citações", em que o único gesto do escritor é "mesclar as escrituras" (BARTHES, 2012a, p. 62). Portanto, não faria sentido tentar decifrar suas intenções, visto que isso poderia significar que o texto teria um significado último, o que não é verdade, dada a sua multiplicidade de sentidos. Barthes, então, defende que o leitor é "um 
lugar onde essa multiplicidade se reúne", de forma que "a unidade do texto não está em sua origem, mas no seu destino" (BARTHES, 2012a, p. 64).

No texto "O estilo e sua imagem", Barthes (2012b) retoma a questão da repetição, mas, nesse caso, relacionada às estruturas formais usadas nos textos, o que muitos chamam de estilo, e que seria responsável por particularizar a escrita de determinado autor. Nesse texto, Barthes trata o estilo como um sistema, que, assim como todos os outros, "tem uma função de naturalização, ou de familiarização ou de domesticação" (BARTHES, 2012b, p. 152), de modo que o estilo literário seria uma "memória coletiva da literatura", criada a partir de modelos. Para ele, escrever seria transformar esses modelos disponíveis de formas, buscando "estruturas frásicas, clichês sintagmáticos, inícios e fechamentos de frases" (BARTHES, 2012b, p. 157-8). O estilo seria, portanto, uma memória, "uma herança fundada em cultura, não em expressividade" (BARTHES, 2012b, p.158).

Outra abordagem se configura em Bakhtin (2011a). Ele fragmenta o ato da criação, separando o autor-criador do autor-pessoa. $\mathrm{O}$ autorcriador seria um "elemento da obra", enquanto o autor-pessoa seria o "elemento do acontecimento ético e social da vida" (BAKHTIN, 2011a, p. 9). O autor é tratado como uma consciência ativa, responsável pela criação da completude da personagem e da obra. Ele seria "a consciência da consciência", já que a sua consciência abarcaria toda a consciência da personagem por meio de um "excedente de visão", isto é, ele teria acesso a todos os elementos da obra, incluindo a tudo de cada personagem em particular, o que seria inacessível a elas (BAKHTIN, 2011a, p. 11).

No capítulo "O problema do autor", Bakhtin traz uma "aura divina" para a estética da criação. $O$ autor passa a ser considerado um organizador do mundo criado, é aquele que consegue dar uma imagem de acabamento para o mundo e para as personagens. Segundo ele, "a atividade estética reúne no sentido o mundo difuso e o condensa em uma imagem acabada e autossuficiente" (BAKHTIN, 2011a, p. 177).

Em "Os gêneros do discurso", a questão do estilo é retratada como estando incondicionalmente ligada ao gênero, já que "o estilo integra a unidade de gênero do enunciado como seu elemento" (BAKHTIN, 2011b, p. 266). Bakhtin observa que alguns gêneros discursivos são menos propícios à singularidade do que outros, como, por exemplo, os 
que requerem uma padronização. A diluição da fronteira da autoria e da singularidade fica ainda mais destacada quando defende que nenhum homem é o Adão mítico, pois não somente o sistema linguístico lhe é anterior, como também vários enunciados que usa o precedem. $\mathrm{O}$ processo de criação, portanto, é em maior ou menor medida, uma assimilação das palavras do outro. Por essa concepção, não se pode compreender inteiramente o estilo de um enunciado sem se considerar suas "tonalidades dialógicas", uma vez que o enunciado "nasce e se forma no processo de interação e luta com os pensamentos dos outros" (BAKHTIN, 2011b, p. 298). O leitor passa a ter, nesse entendimento, um papel importante, apresentando uma relação dialógica com a obra, uma "ativa posição responsiva", concordando, discordando, relacionando-a com outras etc.

Por sua vez, Orlandi (2015) analisa o conceito de autoria à luz da Análise do Discurso, defendendo que o texto "é uma dispersão do sujeito" (p. 68) e que o autor é a função discursiva que o sujeito assume, sendo o responsável por dar uma unidade (ainda que imaginária) ao texto. Sua concepção de autoria difere da concepção foucaultiana, pois, segundo ela, "a própria unidade do texto é efeito discursivo que deriva do princípio da autoria" (ORLANDI, 2015, p. 73), o que implica um alargamento da função-autor, visto que, nesse viés, a autoria é necessária a todo discurso ou, nas palavras da autora, "um texto pode até não ter um autor específico, mas, pela função-autor, sempre se imputa uma autoria a ele" (ORLANDI, 2015, p. 73). Para Orlandi (2012a), ao exercer a função-autor, "o sujeito falante está mais afetado pelo contato com o social e suas coerções", é a "dimensão discursiva que está mais determinada pela relação com a exterioridade (contexto sócio-histórico)", submetendo-se mais às regras institucionais (p. 103) e, por essa razão, estaria mais favorável ao 'apagamento' do sujeito. Já o leitor, que seria "seu polo correspondente", também teria um papel na construção dos significados do texto, visto que também é afetado pelas relações sociais e históricas (ORLANDI, 2015).

Indursky (2001), também pela perspectiva da Análise do Discurso, discute os conceitos de autoria e de leitura, a partir do conceito de texto como "uma heterogeneidade provisoriamente estruturada pelo trabalho discursivo de textualização" (p. 39, grifos da autora). Segundo a autora, o texto tem uma materialidade linguística que aponta para uma exterioridade, constituída por relações contextuais (econômicas, sócio- 
históricas e culturais), intertextuais e interdiscursivas (atravessadas pelos já-ditos ou pela memória discursiva). Assim, ao produzir um texto, o sujeito assume a função de autor, que "mobiliza diferentes relações com a exterioridade e as organiza, dando-lhes a configuração de um texto" (INDURSKY, 2001, p. 30). Essa organização da exterioridade em um texto bem construído produziria um "efeito texto", isto é, uma ilusão de começo, meio e fim, uma ilusão de fechamento, devido a um apagamento "das marcas de 'costura' dessas diferentes alteridades" (INDURSKY, 2001, p. 32) e um "efeito de textualidade", que consiste na retextualização do interdiscurso. Segundo a autora, essa heterogeneidade é provisória, porque o sujeito-leitor, também afetado pela exterioridade, interage com o texto e, ao ressignificá-lo, constrói um novo efeito-texto, tornando-se um sujeito-autor.

A ordem de apresentação dessas concepções se constitui em um caminho crescente de adesão, partindo de uma abordagem mais distante das questões relativas à textualização e chegando a uma concepção em que a interação temática e o papel da articulação já podem ser vislumbrados nas abordagens de Orlandi (2015) e Indursky (2001), e a textualização adquire um papel importante no contorno da concepção de autoria.

Na próxima seção, serão apresentados os pressupostos teóricos da Semântica da Enunciação, a partir da qual fundamentamos as especificidades da perspectiva de autoria que desenvolvemos no presente estudo.

\section{A Semântica da Enunciação}

Apresentaremos os traços de uma abordagem semântica centrada na enunciação. Essa abordagem tem suas raízes nos estudos de Bally (1965), Benveniste (1989) e Ducrot (1988), dentre outros, desenvolvidos na França a partir da segunda metade do século XX. No Brasil, dentre os vários pesquisadores que se dedicam aos estudos enunciativos, destacamos Guimarães (2002). O trabalho que ora apresentamos é um desenvolvimento das abordagens que Dias (2015a, 2015b, 2018) tem empreendido com base na perspectiva de Guimarães.

Os estudos enunciativos desenvolvidos por Guimarães dialogam, principalmente, com Benveniste (1989) e Ducrot (1988). Para Guimarães (2002), a enunciação é concebida como o acontecimento da 
produção de sentidos, que constitui uma temporalidade do presente do enunciar, atravessada por memoráveis (já-ditos) que projetam significações futuras.

Segundo ele, o acontecimento enunciativo ocorre em um espaço de enunciação, que é regulado pela relação desigual entre falantes, "enquanto um espaço político" (GUIMARÃES, 2002, p. 18), que é "incontornável porque o homem fala" (GUIMARÃES, 2002, p. 16). Retornaremos ao conceito de político, na próxima seção, quando tratarmos de ponto de vista.

Os fundamentos dessa perspectiva enunciativa influenciaram os trabalhos de Dias (2015a, 2015b, 2018), pois, assim como Guimarães, Dias concebe a enunciação como o acontecimento da produção de sentidos, perpassado por uma memória de dizeres, que dão suporte a novas significações. $O$ caráter histórico e político da enunciação também é indispensável nesta abordagem.

Dias (2018) defende que nós significamos por meio de referenciais sociais de ordem histórica, os quais podem ser concebidos como perspectivas sociais de percepção da realidade. Nessa abordagem, ainda que os modos de formulação dos sentidos tenham uma dimensão individual, "os modos representativos de se expressar são históricos, compartilhados e expostos à diferença numa sociedade, num território determinado" (DIAS, 2018, p. 21). Portanto, o referencial histórico pode ser "definido como o domínio de ancoragem da significação na língua, a partir do funcionamento das relações sociais" (DIAS, 2018, p. 142). Disso decorre que as demandas enunciativas do presente, que são denominadas pertinência enunciativa nessa visão teórica, tornam-se significativas a partir de referenciais históricos.

A expressão 'pertinência enunciativa' não se relaciona à qualidade do dizer, à relevância ou à adequação, mas ao conceito de 'pertença' ou 'pertencimento'. Conforme Dias,

No cotidiano, nós somos evocados ou acionados a responder, interpretar, a interferir enunciativamente nas situações de enunciação que se nos apresentam. Quando tomamos a palavra, seja no oral, seja no escrito, o fazemos de diferentes maneiras tendo em vista diferentes situações de enunciação. Os nossos modos de 
enunciar, portanto, se adaptam a seu modo de pertencimento às cenas de enunciação do presente (DIAS, 2018, p. 142-143).

Segundo o autor, a adaptação à cena de enunciação do presente do enunciar produziria conformações de dois tipos: conformações interativas, relacionadas principalmente aos atos de fala, e conformações de articulação, relacionadas aos gêneros e sequências textuais. Aquelas se relacionam predominantemente às tipologias de elocução, como desenvolvidas por Austin (1990) ${ }^{1}$, e estas se relacionam aos gêneros textuais, tipologias textuais e às demais formas de textualização.

Como a relação autor/leitor é perpassada pelos textos modelares, que sedimentam formas de leitura e escrita (ORLANDI, 2012b), na próxima seção, apresentaremos uma perspectiva de autoria ancorada nesses dois conceitos apresentados, em uma redação nota 1.000 do ENEM.

\section{O ponto de vista na constituição da autoria}

Como vimos na seção 1 , dois pontos perpassam a maior parte dos estudos dedicados ao conceito de autoria: i) o autor (ou função-autor) tem um papel de organizador textual e ii) a originalidade não é um ponto que se destaca no conceito de autoria. Para Foucault (2000, p. 26), a autoria seria "um princípio de agrupamento do discurso, como unidade e origem de suas significações, como foco de sua coerência"; segundo Bakhtin (2011a, p. 177), "a atividade estética reúne no sentido o mundo difuso e o condensa em uma imagem acabada e auto-suficiente"; Orlandi (2015, p. 73) defende que "a própria unidade do texto é efeito discursivo que deriva do princípio de autoria" e Indursky (2011, p. 39) sustenta que a função-autor "mobiliza diferentes relações com a exterioridade e as organiza, dando-lhes a configuração de um texto", ou, como declara, de um "efeito texto".

Neste trabalho, também defenderemos que o sujeito assume a função-autor no interior do texto que escreve, constituindo-se como um princípio organizador. Isso não implica que a significação seja uma via de mão única, pois, como Indusky (2011) e Orlandi (2015), acreditamos que a significação envolve a função-autor e a função-leitor, mas, neste trabalho, o nosso foco é na função-autor. Também defenderemos que a 
originalidade não é um traço relevante a ser considerado, haja vista a relação da função-autor com os referenciais históricos que circulam socialmente e as conformações a que tem que submeter seu texto. Entretanto, a singularidade do sujeito pode ser observada na construção do ponto de vista, um espaço de subjetividade, malgrado as coerções (sócio-históricas, linguísticas e textuais) a que está submetido ${ }^{2}$.

Advogamos que o ponto de vista constituído pela função-autor é natureza política. Como apresentamos na seção anterior, para Guimarães (2002), o acontecimento enunciativo ocorre em um espaço de enunciação, que é atravessado, de forma incontornável, pelo político. Baseando-se em Orlandi (1990), que relaciona o político ao conflito, e no conceito de político de Rancière (1996), Guimarães (2002, p. 16) define o político como "uma divisão normativa e desigual do real e uma redivisão pela qual os desiguais afirmam seu pertencimento". A base para que o político se instale, segundo o autor, é o conflito, a contradição entre as posições/instituições normativas "que organizam desigualmente o real e a afirmação de pertencimento dos não incluídos" (GUIMARÃES, 2002, p. 17).

Rancière (1996) sustenta que a racionalidade da política é o desentendimento, que não seria um mal-entendido nem um desconhecimento, mas "a disputa sobre o que quer dizer falar constitui a própria racionalidade da situação de palavra" (RANCIÈRE, 1996, p. 12). Conforme o autor, "as estruturas de desentendimento são aquelas em que a discussão de um argumento remete ao litígio acerca do objeto da discussão e sobre a condição daqueles que o constituem como objeto" (RANCIERE, 1996, p.13).

Dessa forma, seguindo o conceito de "política" de Guimarães (2002) e de Rancière (1996), sustentamos que a autoria se constitui na defesa de uma racionalidade sobre o objeto da discussão, que está em disputa em uma determinada "situação de palavra" (nesse caso, a redação do ENEM), provocando uma redivisão/reorganização do real. A defesa de uma racionalidade será tratada como "ponto de vista" e ela se fundamentará em referenciais históricos legitimados, de acordo com $A$ redação do ENEM 2019: cartilha do participante (doravante Cartilha), conformando-se ao modelo de texto exigido pelo exame. Optamos por analisar o conceito de autoria em uma redação nota 1.000 deste exame, pois a "configuração de autoria" é um dos critérios considerados para se atingir a nota máxima e, como esses textos são publicados na 
Cartilha como textos exemplares, legitimam-se como modelos de escrita.

De acordo com a proposta de redação do Exame Nacional do Ensino Médio (ENEM), o candidato tem que redigir um texto dissertativoargumentativo que tenha entre 8 e 30 linhas, na modalidade escrita formal da língua portuguesa, apresentando uma proposta de intervenção que respeite os direitos humanos. Embora o exame não apresente um gênero textual específico, defendemos, como Carvalho (2014), que se trata de um gênero textual próprio, que definiremos como "redação do ENEM", porque é um texto dissertativo-argumentativo em prosa, escrito em uma situação de avaliação, que exige a defesa de um ponto de vista sobre o tema em questão e uma solução para o problema apresentado, a qual não é obrigatória, por exemplo, no artigo de opinião, em que o articulista, além de escrever com antecedência, pode consultar várias fontes, resultando em um texto publicado em veículo da esfera jornalística.

De acordo com a Cartilha (BRASIL, 2019), o texto será avaliado em cinco competências, sendo que os critérios exigidos para se tirar a nota máxima (200 pontos) em cada competência são: na competência 1, exige-se excelência no uso da modalidade escrita formal; na competência 2, é necessário desenvolver uma argumentação consistente, utilizando um repertório sociocultural produtivo, e apresentar excelência no uso do tipo textual exigido; na competência 3, exige-se a apresentação de "informações, fatos e opiniões relacionados ao tema proposto, de forma consistente e organizada, configurando autoria, em defesa de um ponto de vista" (p. 20); a competência 4 demanda um uso variado de elementos coesivos e a competência 5 solicita que seja elaborada uma proposta de intervenção detalhada, relacionada ao tema e à discussão realizada pelo candidato. Portanto, para atender às demandas do exame, é necessário realizar conformações textuais e linguísticas, como o uso da modalidade formal da língua portuguesa escrita e o uso diversificado de conectivos.

Outra exigência do exame é a necessidade de se defender um ponto de vista para a configuração da autoria, a qual estaria relacionada à organização do texto, de acordo a competência 3. Esta competência, segundo a Cartilha (BRASIL, 2019), trata da inteligibilidade textual, que seria garantida pelo reconhecimento de um projeto de texto, definido como "o esquema que se deixa perceber pela organização 
estratégica dos argumentos presentes no texto" (p. 19). Um bom texto seria "aquele no qual é possível perceber a presença implícita de um projeto de texto, ou seja, aquele em que é claramente identificável a estratégia escolhida por quem está escrevendo para defender seu ponto de vista" (BRASIL, 2019, p. 19). Como se pode notar, a Cartilha também relaciona a autoria à mão invisível que organiza o texto, o que Indursky (2001) denominou "efeito texto", que ocorre quando o autor consegue criar uma ilusão de começo, meio e fim, apagando as "marcas da costura".

Ao escolher um ponto de vista, que se explicita pela defesa de uma tese neste gênero textual, escolhe-se uma "racionalidade sobre o objeto da discussão", isto é, o tema da proposta de redação pode ser recortado e analisado de várias formas, mas o candidato tem de se posicionar (politicamente) ao defender seu ponto de vista e, como consequência, precisará mobilizar um repertório sociocultural produtivo, segundo a competência 2.

Na Cartilha (BRASIL, 2019, p. 17), são apresentadas estratégias argumentativas de convencimento, cujo uso poderia ser configurado como repertório sociocultural, quais sejam: "exemplos, dados estatísticos, pesquisas, fatos comprováveis, citações ou depoimentos de pessoas especializadas no assunto, pequenas narrativas ilustrativas, alusões históricas e comparações entre fatos, situações, épocas ou lugares distintos". Podemos notar que esse repertório tem filiação em disciplinas, como as Ciências Naturais, História, Filosofia, Literatura, Artes etc., de forma que podemos considerá-lo como o referencial histórico legitimado pelo exame, pois, se o candidato fizer uso exclusivamente de referenciais não legitimados, ainda que esses discursos estejam filiados a um campo de conhecimento de menor prestígio (por causa do local social de onde partem esses discursos ou por serem considerados "senso comum"), obterá uma nota menor na competência 2. Além do uso obrigatório desses referenciais, é necessário que seu uso seja "produtivo", ou seja, deve ser adequado ao tema e à defesa do ponto de vista.

Considerando os critérios avaliativos do exame e os pressupostos teóricos expostos, passemos à análise da autoria na redação de $\mathrm{LSLL}^{3}$ que figura na "Amostra de redações nota 1.000" da Cartilha (BRASIL, 2019, p. 35). Destacamos que o tema da redação de 2018 foi 
"Manipulação do comportamento do usuário pelo controle de dados na internet".

A Revolução Técnico-científico-informacional, iniciada na segunda metade do século $\mathrm{XX}$, inaugurou inúmeros avanços no setor de informática e telecomunicações. Embora esse movimento de modernização tecnológica tenha sido fundamental para democratizar o acesso a ferramentas digitais e a participação nas redes sociais, tal processo foi acompanhado pela invasão da privacidade de usuários, em virtude do controle de dados efetuado por empresas de tecnologia. Tendo em vista que o uso de informações privadas de internautas pode induzi-los a adotar comportamentos intolerantes ou a aderir a posições políticas, é imprescindível buscar alternativas que inibam essa manipulação comportamental no Brasil.

A princípio, é necessário avaliar como o uso de dados pessoais por servidores de tecnologia contribui para fomentar condutas intolerantes nas redes sociais. Em consonância com a filósofa Hannah Arendt, podese considerar a diversidade como inerente à condição humana, de modo que os indivíduos deveriam estar habituados à convivência com o diferente. Todavia, a filtragem de informações efetivada pelas redes digitais inibe o contato do usuário com conteúdos que divergem dos seus pontos de vista, uma vez que os algoritmos utilizados favorecem publicações compatíveis com o perfil do internauta. Observam-se, por consequência, restrições ao debate e à confrontação de opiniões, que, por sua vez, favorecem a segmentação da comunidade virtual. Esse cenário dificulta o exercício da convivência com a diferença, conforme defendido por Arendt, o que reforça condutas intransigentes como a discriminação.

Em seguida, é relevante examinar como o controle sobre o conteúdo que é veiculado em sites favorece a adesão dos internautas a certo viés ideológico. Tendo em vista que os servidores de redes sociais como Facebook e Twitter traçam o perfil de usuários com base nas páginas por eles visitadas, torna-se possível a identificação das tendências de posicionamento político do indivíduo. Em posse dessa informação, as empresas de tecnologia podem privilegiar a veiculação de notícias, inclusive daquelas de procedência não confirmada, com o fito de reforçar as posições políticas do usuário, ou, ainda, de modificá-las para que se adequem aos interesses da companhia. Constata-se, assim, a possibilidade de manipulação ideológica na rede. 
Portanto, fica evidente a necessidade de combater o uso de informações pessoais por empresas de tecnologia. Para tanto, é dever do Poder Legislativo aplicar medidas de caráter punitivo às companhias que utilizarem dados privados para a filtragem de conteúdos em suas redes. Isso seria efetivado por meio da criação de uma legislação específica e da formação de uma comissão parlamentar, que avaliará as situações do uso indevido de informações pessoais. Essa proposta tem por finalidade evitar a manipulação comportamental de usuários e, caso aprovada, certamente contribuirá para otimizar a experiência dos brasileiros na internet.

Antes de passarmos às discussões realizadas no texto, é necessário apresentar considerações sobre as conformações de articulação. Podese notar que a função-autor se adequa a essas conformações, visto que a produção textual está apropriada ao gênero e ao tipo textual exigidos, à modalidade formal da língua portuguesa escrita, com destaque para um uso diversificado de conectivos.

Também são necessários alguns apontamentos sobre os textos motivadores apresentados na proposta ${ }^{4}$, haja vista que os candidatos constroem sua argumentação tomando-os como base. Esses textos estimulavam os candidatos a concordar com a existência de uma manipulação de dados dos usuários. No texto motivador 1, por exemplo, afirma-se que o problema é "a ilusão de liberdade de escolha que muitas vezes é gerada pelos algoritmos" (BRASIL, 2019, p. 30). No texto 2, defende-se que moderadores filtram os dados dos usuários, controlando o que deve ser excluído da rede. O texto motivador 3 mostra ao candidato que a maior parte dos brasileiros utiliza a internet no Brasil, o que sugere, pela leitura integrada com os demais textos motivadores, que a manipulação de dados pode levar ao controle de uma nação. Já no texto 4, sustenta-se que o controle de dados leva a escolhas influenciadas.

Passemos à análise da autoria na produção textual selecionada. Para introduzir o texto, a função-autor mobiliza referenciais da revolução informacional, que possibilitaram ganhos, como a democratização do "acesso a ferramentas digitais e participação nas redes sociais", e perdas, como a "invasão da privacidade de usuários". Entretanto, como o ponto de vista será ancorado na concordância com as teses defendidas nos textos motivadores, a função-autor utiliza uma oração concessiva, por meio do conector embora, para destacar as perdas desse processo. 
O ponto de vista é apresentado, de forma resumida, na tese do texto e articula os referenciais de "manipulação de dados dos usuários" e "manipulação política", presentes nos textos motivadores, aos referenciais de "intolerância", inseridos pela função-autor, culminando com um apelo para inibir tal manipulação, como se vê a seguir:

Tendo em vista que o uso de informações privadas de internautas pode induzi-los a adotar comportamentos intolerantes ou a aderir a posições políticas, é imprescindível buscar alternativas que inibam essa manipulação comportamental no Brasil.

Para legitimar o uso do referencial histórico de "intolerância", a função-autor apresenta, no segundo parágrafo, a teoria da filósofa Hannah Arendt, que trata a diversidade como inerente à condição humana, e a articula às consequências da filtragem de dados, que produziriam um apagamento da diversidade e, portanto, um aumento da intolerância.

No terceiro parágrafo, a função-autor explica como o controle de dados relaciona-se ao referencial de "manipulação política", ao examinar os procedimentos de controle de dados das redes sociais Facebook e Twitter - que privilegiam certas informações em detrimento de outras com base nos algoritmos (as páginas mais visitadas) - , e conclui que essa saliência pode reforçar as posições políticas do usuário ou modificá-las para que se adequem aos interesses da empresa. A partir disso, constata que existe a "possibilidade de manipulação ideológica na rede".

No último parágrafo, observamos um apelo ao poder legislativo para punir as empresas que manipulam os dados dos usuários, destacandose o modo como deverá ser feito - "por meio da criação de uma legislação específica e da formação de uma comissão parlamentar" - e, esclarecendo sua dupla finalidade: "evitar a manipulação comportamental de usuários e, caso aprovada, certamente contribuirá para otimizar a experiência dos brasileiros na internet".

Podemos concluir que a função-autor nesta redação nota 1000 configura-se na delimitação do ponto de vista (materializado na tese), o qual é ancorado na articulação dos referenciais históricos dos textos 
motivadores ("manipulação de dados dos usuários" e "manipulação política") e do sujeito ("intolerância", por meio da citação de Hannah Arendt) que se tornam pertinentes na relação com as conformações interativas selecionadas pela função-autor de concordar com a filósofa que a "diversidade é inerente à condição humana", de discordar da filtragem de dados e associá-la ao favorecimento da segmentação da comunidade virtual, de examinar os procedimentos adotados pelas redes sociais e concluir que as empresas podem destacar certas notícias, o que a leva a constatar que pode haver manipulação ideológica e a apelar para mecanismos de punição conduzidos pelo poder legislativo, esclarecendo as finalidades dessa punição.

A análise da redação nota 1000 nos mostrou que a assunção da autoria na redação do ENEM, como definida neste artigo, é possível, já que o exame exige que o candidato defenda um ponto de vista, possibilitando a defesa de uma racionalidade sobre o tema em questão, o que favorece a subjetividade na escolha dos referenciais mobilizados e na articulação desses referenciais por meio das conformações interativas e de articulação. A análise de textos exemplares é importante, em primeiro lugar, pois os docentes de Língua Portuguesa têm que analisar se as propostas de redação dos exames de seleção permitem a construção da autoria, e, em segundo lugar, devemos nos lembrar de que os discentes e os docentes sofrem as coerções desses textos modelares e, ainda que seja necessário ultrapassá-los, é preciso entendê-los.

\section{Considerações finais}

Neste artigo, apresentamos uma proposta de análise da autoria à luz dos pressupostos teóricos da Semântica da Enunciação, desenvolvidos por Dias (2018), o qual sustenta que a produção de sentidos ocorre no cruzamento dos referenciais históricos com as demandas do presente da enunciação. De acordo com o autor, os nossos dizeres se amparam em um suporte institucional, têm uma filiação, visto que as práticas discursivas e sociais são organizadas por um sistema de regulações, que define o que é permitido, proibido, necessário, evitável, favorecido, enfim, os saberes que são válidos, o que pode ou não ser dito etc. Esse sistema constitui os referenciais históricos, que ancoram a mobilização dos sentidos, e se tornam pertinentes, quando somos instados a 
responder às demandas sociais, como concordar, discordar, concluir, negar, afirmar etc. A reação a essas demandas sofre conformações interativas e de constituição de textualidade, segundo tipologias e normatividades de articulação.

A partir dessas conformações, propomos que a autoria se constitui na delimitação do ponto de vista, que, neste artigo, foi definido como uma ação política, conceito entendido conforme as definições de Guimarães (2002) e de Rancière (1996), ou seja, como a defesa de uma racionalidade sobre o objeto da discussão, que está em disputa em uma determinada "situação de palavra".

Especificamente, no que se refere às conformações interativas, ancoradas em referenciais, a função-autor se constitui de maneira mais consistente e visível na medida em que se definem posições frente à demanda temática que se apresenta para ele no momento da produção de atos de fala constitutivos de um texto opinativo. Essa é a configuração da pertinência enunciativa, em sua primeira dimensão.

Por sua vez, é no âmbito das conformações de articulação que se definem os contornos da textualidade, tanto do ponto de vista da tipologia, quanto do ponto de vista das articulações internas ao texto, no exercício da textualização, isto é, na tessitura do posicionamento advindo dos referenciais históricos frente ao desenvolvimento da temática que se coloca em desafio na escrita. Essa é a configuração da pertinência enunciativa, em sua segunda dimensão.

Dessa maneira, a defesa do ponto de vista é ancorada por referencias históricos e se tornam pertinentes por meio de conformações interativas e de articulação. A análise de uma redação nota 1.000 do exame de 2018 permitiu ver que este conceito de autoria traz reflexões importantes para se pensar a função-autor nas produções escritas escolares e nos exames de seleção.

\section{Referências bibliográficas}

AUSTIN, J. L. Quando dizer é fazer: palavras e ação. Porto Alegre: Artes Médicas, 1990.

BAKHTIN, M. (2011a). "O autor e a personagem na atividade estética”. In: BAKHTIN, M. Estética da criação verbal. 6. ed. São Paulo: Martins Fontes, 2011a, p. 3-192. 
BAKHTIN, M. "Os gêneros do discurso". In: BAKHTIN, M. Estética da criação verbal. 6. ed. São Paulo: Martins Fontes, 2011b, p. 261306.

BALLY, C. Linguistique general et linguistique française. 4. ed. Berne: Éditions A. Francke, 1965.

BARTHES, R. "A morte do autor". In: BARTHES, R. O rumor da língua. 3. ed. São Paulo: Martins Fontes, 2012a, p. 57-64.

BARTHES, R.. "O estilo e sua imagem". In: BARTHES, R. O rumor da língua. 3. ed. São Paulo: Martins Fontes, 2012b, p. 147-159.

BENVENISTE, É. Problemas de linguística geral II. 2. ed. Campinas: Pontes, 1989.

BRASIL. Instituto Nacional de Estudos e Pesquisas Educacionais Anísio Teixeira (Inep). A redação no Enem 2019: cartilha do participante. Brasília, 2019. Disponível em: http://download.inep.gov.br/educacao basica/enem/downloads/2019/r edacao_enem2019_cartilha_participante.pdf. Acesso em: 20 jul. 2020. CARVALHO, G. C. Memórias das minhas doces aulas de Língua Portuguesa: aplicando teorias no "fazer docente". Curitiba: Appris, 2014.

DIAS, L. F. "Acontecimento Enunciativo e Formação Sintática". In: Revista Línguas e Instrumentos Linguísticos. Campinas, n. 35, p. 99138, jan-jun, 2015a.

DIAS, L. F. "Língua e nacionalidade no Brasil na primeira metade do século XX". In: Polifonia, Cuiabá, v. 22, n. 31, p. 11-31, jan./jul, 2015b.

DIAS, L. F. Enunciação e relações linguísticas. Campinas: Pontes, 2018.

DUCROT, O. "Esboço de uma teoria polifônica da enunciação". In: DUCROT, O. O dizer e o dito. Campinas: Pontes, 1988.

FOUCAULT, M. A ordem do discurso. 6. ed. São Paulo: Loyola, 2000.

FOUCAULT, M. O que é um autor? 10. ed. Lisboa: Veja, 2018 GUIMARÃES, E. Semântica do acontecimento: um estudo enunciativo da designação. Campinas: Pontes, 2002.

INDURSKY, F. "Da heterogeneidade do discurso à heterogeneidade do texto e suas implicações no processo da leitura". In: ERNSTPEREIRA, A; FUNCK, S. B. A leitura e a escrita como práticas discursivas. Pelotas: Educat, 2011, p. 27-42. 
ORLANDI, E. "Tipologias de discurso e regras conversacionais". In: ORLANDI, E. A linguagem e seu funcionamento: As formas do discurso. 2. ed. Campinas: Pontes, 1987, p.149-175.

ORLANDI, E. "Nem escritor, nem sujeito, apenas autor". In: ORLANDI, E. Discurso e leitura. 9. ed. São Paulo: Cortez, 2012a. p. 100-111.

ORLANDI, E. Significação, leitura e redação. In: ORLANDI, E. Discurso e leitura. 9. ed. São Paulo: Cortez, 2012b, p. 112-124.

ORLANDI, E. Análise de discurso: princípios e procedimentos. 12. ed. Campinas: Pontes, 2015.

RANCIĖRE, J. O desentendimento: política e filosofia. São Paulo: Ed. 34. 1996.

\section{Notas}

* Graduada em Letras e em Língua Espanhola pela Universidade Federal de Minas Gerais (UFMG). Mestre e doutora em Estudos Linguísticos pela UFMG. Professora efetiva de Língua Portuguesa e Língua Espanhola no Instituto Federal de Minas Gerais (IFMG) - campus Santa Luzia.

** Doutor em Linguística pela Universidade Estadual de Campinas (UNICAMP). Professor Titular da Universidade Federal de Minas Gerais (UFMG) e pesquisador bolsista do Conselho Nacional de Desenvolvimento Científico e Tecnológico (CNPq). ${ }^{1}$ Opondo-se a uma tradição que defende que as declarações são descrições de fatos, Austin (1990) defende a tese de que falar é fazer. Destaca, entretanto, que, para que esses atos sejam adequados, é necessário que satisfaçam condições de felicidade (sejam proferidos em um ato aceito socialmente, pelos interlocutores adequados para essa cerimônia, usando-se palavras esperadas nessas circunstâncias de proferimento etc.). Por exemplo, ao dizer "aceito", em uma cerimônia de casamento (e satisfeitas as condições de felicidade da sentença), não estou descrevendo o ato, mas me casando. Austin cria cinco classes de proferimentos, de acordo com sua força ilocucionária, são eles: veriditivos, responsáveis por dar um veredito (oficial ou não, como em "condenar"); exercitivos, relacionados à tomada de decisões (como "designar", "votar", "avisar" etc.), comissivos, em que as pessoas se comprometem a realizar algo (como "prometer", "compactuar", "apostar" etc.); comportamentais, em que se demonstra uma atitude diante de uma conduta ("pedir desculpas", "elogiar", "desafiar" etc.) e expositivos, empregados para esclarecer um proferimento e expressar opiniões (como "contestar" e "argumentar").

${ }^{2}$ Neste artigo, analisamos o conceito de autoria em um texto, que pode ser caracterizado como dissertativo-argumentativo ou, conforme Orlandi (1987), um texto em que predomina o discurso polêmico, i.e., textos em que a polissemia é controlada e a reversibilidade dos interlocutores ocorre em determinadas condições. É necessário 
analisar outras tipologias de textos para ver o alcance de nossas considerações sobre autoria.

3 Ainda que o nome do candidato esteja presente na Cartilha (BRASIL, 2019), decidimos apresentar apenas as suas iniciais neste texto.

${ }^{4}$ Os textos motivadores estão disponíveis em Redação do Enem 2019: Cartilha do Participante (BRASIL, 2019, p. 30). 